\title{
Enhancing the resilience to flooding induced by levee breaches in lowland areas: a methodology based on numerical modelling
}

\author{
Alessia Ferrari, Susanna Dazzi, Renato Vacondio, and Paolo Mignosa \\ Department of Engineering and Architecture, University of Parma, Parco Area delle Scienze 181/A, 43124 Parma, Italy
}

Correspondence: Alessia Ferrari (alessia.ferrari@unipr.it)

Received: 18 April 2019 - Discussion started: 22 May 2019

Revised: 9 October 2019 - Accepted: 4 December 2019 - Published: 13 January 2020

\begin{abstract}
With the aim of improving resilience to flooding and increasing preparedness to face levee-breach-induced inundations, this paper presents a methodology for creating a wide database of numerically simulated flooding scenarios due to embankment failures, applicable to any lowland area protected by river levees. The analysis of the detailed spatial and temporal flood data obtained from these hypothetical scenarios is expected to contribute both to the development of civil protection planning and to immediate actions during a possible future flood event (comparable to one of the available simulations in the database) for which real-time modelling may not be feasible. The most relevant criteria concerning the choice of mathematical model, grid resolution, hydrological conditions, breach parameters and locations are discussed in detail. The proposed methodology, named RESILIENCE, is applied to a $1100 \mathrm{~km}^{2}$ pilot area in northern Italy. The creation of a wide database for the study area is made possible thanks to the adoption of a GPU-accelerated shallow-water numerical model which guarantees remarkable computational efficiency (ratios of physical to computational time up to 80) even for high-resolution meshes (2.5$5 \mathrm{~m})$ and very large domains $\left(>1000 \mathrm{~km}^{2}\right)$.
\end{abstract}

\section{Introduction}

Flood events adversely affect communities living in floodprone areas, causing huge damage in terms of economic losses and human lives. Recent studies identified a rising trend in flood frequency and affected population in the past few decades (Kundzewicz et al., 2013; Paprotny et al., 2018) and suggested that global warming will determine a growing occurrence of extreme flood events (Alfieri et al., 2015) and the related damage (Dottori et al., 2018) in the future.

Among the possible causes of flooding, levee breaching deserves special attention. Due to the well-known "levee effect", structural flood protection systems, such as levees, determine an increase in flood exposure. In fact, the presence of this hydraulic defence creates a feeling of safety among people living in flood-prone areas, resulting in the growth of settlements and in the reduction of preparedness and hence in the increase in vulnerability in those areas (Di Baldassarre et al., 2015). As a result, more people are exposed to less frequent but more devastating floods, for which the statistical frequency is difficult to assess due to the historical changes in river systems (Black, 2008).

Moreover, the presence of levees causes a reduced flood attenuation, which in turn increases the damage when a breach occurs (Heine and Pinter, 2012). Despite all the efforts adopted in embankment design, maintenance and monitoring, the residual risk associated with levee-breach flooding in the surrounding areas cannot be neglected, and its evaluation is hence gaining attention worldwide (Huthoff et al., 2015; Pinter et al., 2016). Nowadays, mathematical models for flood simulation, which solve physically based equations for hydrodynamics (Teng et al., 2017), represent an essential instrument for flood hazard and risk assessment (e.g. Apel et al., 2004; Qi and Altinakar, 2011), including the residual risk due to levee breaches (Vorogushyn et al., 2010). Numerical modelling can contribute to drawing up flood risk management plans with prevention and protection measures to reduce flood-related damage and enhance resilience (defined as the ability of the system to recover from flooding in floodprone areas; De Bruijn, 2005). The accurate predictions of inundation scenarios provided by numerical simulations can 
also be useful for assessing civil protection and adaptation strategies (Jongman et al., 2018) and emergency planning during flood events (Tarrant et al., 2005; Dulebenets et al., 2019a, b).

For civil protection purposes, real-time numerical modelling is the most well-suited solution when dealing with large river basins whose flood events last several days, considering that the simulation time (a few hours) is usually much smaller than the physical duration of the flood. Moreover, hydrologic inputs or water level measurements from upstream river sections can be used as boundary conditions to predict the flood propagation along the river. Conversely, in small-medium river basins with short-lasting floods (less than $1 \mathrm{~d}$ ), real-time simulations are much more challenging because of the following: (i) they have to be based on rainfall-runoff models and weather forecasts, which are characterized by high uncertainties, and (ii) their computational and physical times are characterized by the same order of magnitude. Focusing on levee failures, the real-time prediction of possible breach locations is very difficult in practice due to the complexity of the breaching process and to the uncertainties in the embankment material characteristics (often heterogeneous and with unknown local discontinuities), especially for small rivers. Considering all these limitations, the creation of an offline database of hypothetical flooding scenarios constitutes an alternative solution to real-time forecasting based on integrated hydrologic-hydraulic modelling.

This paper presents a methodology for assessing the flooding scenarios induced by levee breaches with the purpose of increasing resilience in lowland areas. For a given exposed area, the RESILIENCE project (REsearch on Scenarios of Inundation of Lowlands Induced by EmbaNkment Collapses in Europe) aims at the creation of a wide database of highresolution numerical simulations concerning several hypothetical flood scenarios, each one characterized by a specific breach location and an upstream discharge hydrograph with an assigned return period. While previous studies combined the results of different scenarios in order to create probabilistic flood hazard and flood risk maps (Di Baldassarre et al., 2009; Vorogushyn et al., 2010), in this work breach scenarios are not associated with their probability of occurrence. In fact, the focus of this study is not on flood hazard mapping but on the evaluation of flood dynamics, arrival times, and maximum water depths and velocities, required for the definition of civil protection strategies, which should be equally effective regardless of the event probability, breach failure mechanism, etc. Accurate simulation results are obtained thanks to the adoption of high-resolution meshes and of a robust and efficient numerical model named PARFLOOD (Vacondio et al., 2014; Vacondio et al., 2017).

The methodology is applied to a study area in northern Italy, bounded by the Po River and by its two tributaries Secchia and Panaro, which was affected by levee-breach flooding in the past (Vacondio et al., 2016). General guidelines for the application of the procedure and details on the criteria adopted for the pilot area are reported. Moreover, a few examples of simulation results are provided, and their possible practical use is discussed.

The paper is organized as follows: in Sect. 2, the RESILIENCE project is presented, and the most important features and requirements of the methodology are described in detail. Section 3 illustrates the application to the pilot area, together with some examples of the results. The assumptions, the advantages and the implications of the methodology are discussed in Sect. 4, and concluding remarks are finally outlined in Sect. 5.

\section{Flooding scenarios induced by levee breaches: the RESILIENCE project}

The RESILIENCE project aims at defining a new methodology for mapping flood scenarios due to levee breaches, which can be helpful for improving preparedness and supporting the development of technical and scientific tools for emergency planning and management, consistent with the EU Floods Directive 2007/60/CE. Several breach locations along a leveed river are preliminarily identified, and multiple discharge hydrographs, characterized by different return period, are considered. Each combination of breach position and upstream boundary condition corresponds to a simulated flood scenario. In this way, a large database describing different hypothetical real levee-breach events in that area is created. The results of these simulations, made available to public administrations, can be fundamental not only for emergency planning but also for taking appropriate actions of civil protection in the course of real flood events.

In the following sections, the most important assumptions of the methodology concerning model selection, spatial resolution, hydrological conditions, breach locations and modelling are discussed thoroughly. Moreover, the most relevant simulation outputs and their usefulness for civil protection purposes are described.

\subsection{Numerical model}

\subsubsection{Background}

Free-surface flows are traditionally described by means of the shallow-water equations (SWEs), i.e. depth-averaged mass and momentum conservation laws (Toro, 2001), which can be written either in one-dimensional (1-D) or in 2-D form. In the past, the high computational effort required to perform fully 2-D simulations led to the development of 1D-2-D models, which separate the river, described by means of a 1-D model, and the flood-prone area, where a 2-D model is adopted because in this region no preferential flow direction can be determined a priori.

However, the adoption of either 1-D and 2-D uncoupled (Di Baldassarre et al., 2009; Masoero et al., 2013; Mazzoleni et al., 2013) or coupled (e.g. Gejadze and Monnier, 2007; 
Morales-Hernández et al., 2013; Bladé et al., 2012) models may lead to inaccurate results. In the former case, backwater effects near the breach location, which can reduce the outflow discharge or even reverse the flow (Viero et al., 2013), are not captured, whereas in the latter case the need of defining the coupling location a priori makes the 1-D-2-D model less flexible than a fully 2-D model. Besides this, the flow field becomes markedly 2-D after the breach opening, both inside and outside the river region, and a 1-D model cannot predict the outflowing discharge accurately.

Focusing on the 2-D SWEs, several models adopt a diffusive approach to simplify the original formulation (e.g. LISFLOOD; Horritt and Bates, 2002). However, this does not always guarantee an overall accuracy comparable to that obtained from models which solve the full SWEs, particularly when supercritical flows and hydraulic jumps need to be modelled (Hunter et al., 2008; Neal et al., 2012; Costabile et al., 2017), as often occurs when a breach opens. On the other hand, if the complete equations are written in conservative form, explicit finite volume (FV) schemes can be adopted (Toro, 2001). These methods have the advantage of reproducing both subcritical and supercritical flows, of incorporating the propagation of shock-type discontinuities automatically, and of including robust treatments of wet and dry fronts and irregular topography (Liang and Marche, 2009).

The high computational cost of fully 2-D models based on complete SWEs has prevented their extensive use in simulating large domains $\left(>100 \mathrm{~km}^{2}\right)$ with high-resolution meshes $(5-10 \mathrm{~m})$ until a few years ago, when parallelization techniques started being applied to SWE models (Sanders et al., 2010). Nowadays, expensive supercomputers are not even required, since the use of graphics processing units (GPUs) (Brodtkorb et al., 2012; Lacasta et al., 2014; Vacondio et al., 2014; Vacondio et al., 2017; Conde et al., 2017) limits hardware requirements to a standard workstation equipped with a video card. The execution time of a GPU-parallelized code can be reduced up to 2 orders of magnitude compared to the CPU serial version of the same code (Castro et al., 2011; Vacondio et al., 2014; García-Feal et al., 2018).

\subsubsection{The PARFLOOD model}

Following this discussion, a GPU-accelerated fully 2-D model, such as PARFLOOD (Vacondio et al., 2014; Vacondio et al., 2017), is considered best suited for the purposes of this work and is adopted for the present application. The model solves the complete 2-D SWEs written in integral form (Toro, 2001):

$$
\frac{\partial}{\partial t} \int_{A} \boldsymbol{U} d A+\int_{C} \mathbf{H} \cdot \boldsymbol{n} d C=\int_{A}\left(\boldsymbol{S}_{0}+\boldsymbol{S}_{f}\right) d A,
$$

where $t$ is the time, $A$ and $C$ are the area and boundary of the integration volume, respectively, $\boldsymbol{U}$ is the vector of conserved variables, $\mathbf{H}=(\boldsymbol{F}, \boldsymbol{G})$ is the tensor of fluxes in the $x$ and $y$ directions, and $\boldsymbol{n}$ is the outward unit vector normal to $C$, while $\boldsymbol{S}_{0}$ and $\boldsymbol{S}_{f}$ are the bed slope and friction source terms, respectively. In order to obtain a well-balanced scheme, the terms $\boldsymbol{U}, \boldsymbol{F}, \boldsymbol{G}, \boldsymbol{S}_{0}$ and $\boldsymbol{S}_{f}$ are defined according to the formulation of Liang and Marche (2009) as follows:

$$
\begin{aligned}
& \boldsymbol{U}=\left[\begin{array}{c}
\eta \\
u h \\
v h
\end{array}\right], \boldsymbol{F}=\left[\begin{array}{c}
u h \\
u^{2} h+\frac{1}{2} g\left(\eta^{2}-2 \eta z\right) \\
u v h
\end{array}\right], \\
& \boldsymbol{G}=\left[\begin{array}{c}
v h \\
v^{2} h+\frac{1}{2} g\left(\eta^{2}-2 \eta z\right)
\end{array}\right], \boldsymbol{S}_{0}=\left[\begin{array}{c}
0 \\
-g \eta \frac{\partial z}{\partial x} \\
-g \eta \frac{\partial z}{\partial y}
\end{array}\right], \\
& \boldsymbol{S}_{f}=\left[\begin{array}{c}
0 \\
-g h \frac{n_{f}^{2} u \sqrt{u^{2}+v^{2}}}{h^{4 / 3}} \\
-g h \frac{n_{f}^{2} v \sqrt{u^{2}+v^{2}}}{h^{4 / 3}}
\end{array}\right],
\end{aligned}
$$

where $h$ is the flow depth, $z$ is the bed elevation and $\eta=h+z$ is the water surface elevation; moreover, $u$ and $v$ are the velocity components along the $x$ and $y$ directions, respectively, $g$ is the acceleration due to gravity, and $n_{f}$ is Manning's roughness coefficient.

Equations (1) and (2) are discretized using an explicit FV scheme, and both first- and second-order accurate approximations in space and time can be selected in the PARFLOOD model. The adoption of a depth-positive MUSCL extrapolation at cell boundaries (Audusse et al., 2004), with the minmod slope limiter and the second-order Runge-Kutta method, ensures the second-order accuracy in space and time, respectively. Flux computation is performed using the HLLC approximate Riemann solver (Toro, 2001), and the correction proposed by Kurganov and Petrova (2007) to avoid non-physical velocity values at wet and dry fronts is applied. Finally, the slope source term is discretized by means of a centred approximation (Vacondio et al., 2014), while for the friction source term the implicit formulation proposed by Caleffi et al. (2003) is adopted. The computational grid can be either Cartesian or Block Uniform Quadtree (BUQ; see Vacondio et al., 2017), which is a nonuniform structured mesh.

With the aim of reducing the computational times, the code is written in the Compute Unified Device Architecture (CUDA) language, i.e. a framework for GPU-based parallel computing introduced by NVIDIA ${ }^{\mathrm{TM}}$. This high-level language allows for the exploitation of both hardware resources: the CPU (the host) and the GPU (the device). The good computational performance of this code for field applications was assessed in previous works (Vacondio et al., 2016; Dazzi et al., 2018; Dazzi et al., 2019; Ferrari et al., 2018; Ferrari et al., 2019).

\subsection{Topographic data and spatial resolution}

When levee-breach-induced floods in lowland areas are modelled, a high-resolution mesh is often necessary to describe 
the relevant terrain features typical of man-made landscapes (e.g. roads, railways, channels and embankments). Highresolution topographic information for large areas can be obtained from new remote sensing techniques, such as light detection and ranging (LiDAR) and the Shuttle Radar Topography Mission (SRTM), which provide raw data for the generation of digital terrain models (DTMs). LiDAR-based DTMs are nowadays available for public access for most flood-prone areas in Europe, and meshes derived from these data (even coarsened) often provide the most accurate results for flood modelling (Md Ali et al., 2015).

DTM grids can include billions of cells; however, the number of cells (and thus the runtimes) can be decreased by performing a moderate downsampling (e.g. reducing the grid size from $0.5-1$ to $2-5 \mathrm{~m}$ ) and by adopting non-uniform meshes, either unstructured (Liang et al., 2008; Sætra et al., 2015) or structured (Vacondio et al., 2017). In fact, in urban and suburban areas, the presence of road and railway embankments can influence the flood dynamics significantly, and the bathymetry near these elements should be at a high resolution $(2-5 \mathrm{~m})$. On the other hand, for uniform rural areas a lower resolution (e.g. $10-50 \mathrm{~m}$ ) can be used without impairing the overall accuracy.

It is relevant to note that high-resolution DTMs can be exploited thanks to the availability of parallel 2-D codes; until a few years ago, traditional 2-D and 1-D-2-D models usually adopted a low resolution of the order of 50-100 m for flood-prone areas in order to reduce the computational times (Aureli and Mignosa, 2004; Aureli et al., 2005; Vorogushyn et al., 2010; Masoero et al., 2013; Mazzoleni et al., 2013; Huthoff et al., 2015).

\subsection{Upstream and downstream boundary conditions}

Discharge hydrographs with a specific return period are assigned as the upstream boundary condition. Sometimes these hydrographs are already available from previous hydrological studies and can be provided by local river basin authorities; otherwise, they can be derived from rainfall-runoff modelling or from statistical analyses of recorded discharge hydrographs (e.g. Tomirotti and Mignosa, 2017).

For the purpose of this study, multiple hydrological conditions should be considered in order to cover possible configurations characterized by different breach triggering mechanisms, flood volumes, etc. At least two different discharge hydrographs should be considered for each breach location even though the simulation database can be extended with more hydrological inputs if needed. The first case ("inflow A") corresponds to the condition for which the water surface elevation reaches the levee crest somewhere along the river, thus generating overtopping. The second configuration ("inflow B") concerns a flood event with a lower return period, for which the levee is never overtopped, but other mechanisms might induce the levee collapse. In fact, earthen levees can also experience breaching for piping and inter- nal erosion processes, even when water levels remain below the levee crest. Besides this, the dens of burrowing animals (e.g. porcupine, badger and nutria) were recently identified as another possible cause for breach triggering (Viero et al., 2013; Orlandini et al., 2015). Incidentally, the collapse of an embankment during a flood event with a relatively low return period can be very threatening for human lives because the highest warning thresholds may not be reached, and the population can be unprepared to face flooding.

The choice of the return period for inflows A and B is river-dependent because it is influenced by the design return period of the levee system, by the presence of other flood control structures, etc. In general, preliminary simulations of the propagation of flood waves with different return periods (e.g. 10, 20, 50, 100, 200 and 500 years) for each river should be performed, and the event that corresponds to incipient overtopping can be identified as inflow A. Then, a higher frequency hydrograph can be selected as inflow B in order to consider levee collapses due to piping or other mechanisms during a flood event that does not induce overtopping (for example, when a specific freeboard is guaranteed).

The discharge hydrographs thus obtained are imposed as the upstream boundary condition for the levee-breach scenarios. The downstream boundary condition also deserves special attention. In fact, downstream of the breach location, the discharge may reduce or even fall to zero and reverse, but the water depth does not necessarily reduce accordingly. Hydraulic gradient and inertia can play a significant role, and the stage-discharge relationships at downstream sections may be characterized by a strong loop effect (D'Oria et al., 2015). This leads to the suggestion that, if a single-valued rating curve is imposed as outflow boundary condition, it should be assigned at the farthest possible section downstream from the breach location (even if some criteria concerning the optimal location of a downstream unique rating curve were studied; e.g. Singh et al., 1997).

\subsection{Levee-breach location and modelling}

Several breach locations must be identified along the river levees so that a real event can be associated with one of the simulated scenarios. The distance between two consecutive breach positions should be selected considering the river dimensions, the presence of urban settlements, the flood-prone area topography, and the possible presence of roads and embankments influencing the inundation dynamics.

The description of the gradual opening of the levee breach must be somehow included in the 2-D modelling, since the hypothesis of instantaneous break is not realistic for river embankments. Among the available approaches in the literature, which also include the coupling of the SWEs with a sediment transport model (Faeh, 2007), or with an erosion law (Dazzi et al., 2019), the simple "geometric" approach is selected in this work for two reasons. First, the uncertainties about the geotechnical parameters of the embankment and the com- 
plexity of the breaching process (three-dimensionality, interactions between erosion, infiltration, bank stability, etc.) can be neglected. Second, this method was successfully applied to a real test case (Vacondio et al., 2016), and a similar approach is often adopted for 1-D and 2-D coupled models, especially in the context of flood hazard assessment (e.g. Vorogushyn et al., 2010; Mazzoleni et al., 2013). Thus, in the RESILIENCE project the breach evolution is modelled by varying the local topography in time assuming a trapezoidal opening that widens and deepens from the crest of the embankment to the ground elevation; the breach geometric dimensions (i.e. width) and opening time are given as input parameters.

The two breach parameters should be set consistently with historical data, if available (e.g. Nagy, 2006; Vorogushyn et al., 2010; Govi and Maraga, 2005), or hypothesized according to the river and embankment characteristics. A breach final width of the order of tens to hundreds of metres is often assumed in the literature (Apel et al., 2006; Kamrath et al., 2006). As for the breach development time, very few field observations are available, and values in the range of 1-3h are often reported (Apel et al., 2006; Alkema and Middelkoop, 2005). The impact of the parameters' uncertainty on the results should be evaluated for at least one hydrological scenario, by means of a probabilistic treatment (Apel et al., 2006; Vorogushyn et al., 2010; Mazzoleni et al., 2013) or a sensitivity analysis (Kamrath et al., 2006; Huthoff et al., 2015).

For each breach location and return period, the triggering time for breach opening should be selected after preliminary simulations and corresponds to the moment when either overtopping or the peak water surface elevation is observed at the breach location.

Finally, simulations must be extended in time long enough to capture the flooding evolution in the lowland, which is actually the goal of the presented methodology. The selection of this temporal interval should be guided by considerations of the flood duration in the river, of the inundation dynamics, and of the fact that drainage operations and/or breach closure would start at some point.

\subsection{Outputs}

The outcomes of the modelled scenarios could help the civil protection activities for emergency planning and/or at the occurrence of an event similar to one of those already modelled. Arrighi et al. (2019) recently presented a framework that integrates hydrologic-hydraulic modelling with human safety and transport accessibility evaluations, applied to a small municipality near Florence (Italy), and confirmed the usefulness of detailed spatial and temporal flood data provided by numerical modelling for civil protection purposes. Thus, the first mandatory output concerns spatial and temporal information about the flood dynamics in the lowland area, which can be visualized as an animation of the inundation pattern or as a sequence of frames at selected times.

Other useful indicators for evaluating the flood severity for each scenario include the maps of arrival times of the wetting front, maximum water depths (and/or water surface elevations), maximum velocities, and a hazard index which combines simultaneous water depth and velocity. In general, these maps can be opened in a GIS environment and overlapped with layers of data (e.g. about population, transportation, buildings, critical and vulnerable structures, etc.) to analyse the possible flood impacts on the territory, with the aim of increasing the resilience in the area. First, information about the maximum water depth allows for the definition of the affected areas as well as the identification of escape routes and safety zones where assembly points can be organized. On the other hand, in areas where only shallow water levels can be expected, people can simply be instructed to protect their homes with anti-flood barriers to prevent water from damaging their property. Besides this, analysis of the inundation dynamics can reveal possible service interruptions and disturbance to road accessibility, which can also prevent rescue operations; in this way, alternative routes can be identified.

Moreover, the maximum flow velocity map should not be neglected because high velocities can reduce the stability of vehicles and pedestrians, increasing the hazard for human lives (Milanesi et al., 2015). In general, the most important results for quantifying the hazard for human lives are the maximum simultaneous water depth and velocity, which can be represented in terms of the Froude number, total head, total force and/or total depth. This last indicator, which represents the water depth at rest $D$ whose static force is equivalent to the total force of the flow, is evaluated as follows (Aureli et al., 2008; Ferrari et al., 2019):

$$
D(t)=h(t) \sqrt{1+2 F r^{2}(t)},
$$

where $h(t)$ represents the water depth and $\operatorname{Fr}(t)$ the Froude number at time $t$.

Finally, the map of the arrival times of the wetting front can be useful for early warning and for establishing the timeline for the evacuation procedures, in particular for vulnerable people (older adults, hospitalized patients, etc.). The offline analysis of the simulation results, on the other hand, can help in the identification of possible strategies to reduce the damage, as for example the adoption of movable defence systems (e.g. flood barriers) to preserve lowland urban settlements from flooding or other emergency interventions to drain water (e.g. pumping and relief cuts). Selected strategies can also be tested numerically to verify their effectiveness. 


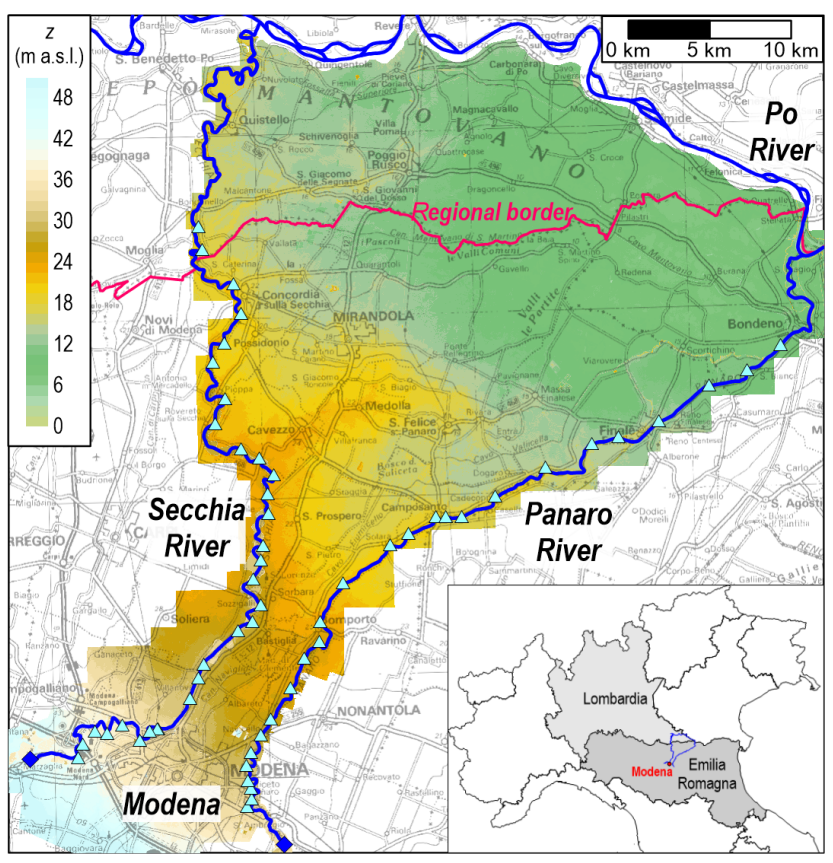

Figure 1. Map of the pilot area (Emilia-Romagna and Lombardia regions, northern Italy): rivers are represented in blue, the breach locations along the Secchia and Panaro rivers are indicated as triangles in cyan, and the terrain elevation contour map is also depicted. The topographic map in background is made available by EmiliaRomagna region at https://geoportale.regione.emilia-romagna.it/it (last access: 8 January 2020).

\section{Application of the RESILIENCE project to a pilot area in northern Italy}

In this section, an example of application of the proposed methodology is presented. The pilot area for the RESILIENCE project (Fig. 1) is at the boundary of two regions (Emilia-Romagna and Lombardia) in northern Italy. This territorial unit is about $1100 \mathrm{~km}^{2}$ wide and is delimited by the Po River (north) and by its two right tributaries Secchia (west) and Panaro (east). The city of Modena bounds the area to the south. This lowland area can be potentially affected by flooding events caused by breaches from the $83 \mathrm{~km}$ long right levee of the Secchia River and/or from the $67 \mathrm{~km}$ long left levee of the Panaro River.

This study area was selected for several reasons. First, the latest report of the Italian National Institute for Environmental Protection and Research (ISPRA, 2018) showed that Emilia-Romagna is the Italian region with the highest level of exposed population (up to 2.7 million exposed inhabitants out of 4.3), buildings and areas for both high (return period of 20-50 years) and medium (return period of 100-200 years) flood frequency. Moreover, the middle-lower basin of the Po River was subject to levee-breach-induced floods several times in the last 150 years, either from the main river levees or from its leveed tributaries (e.g. Di Baldas- sarre et al., 2009; Masoero et al., 2013; D'Oria et al., 2015; Dazzi et al., 2019), often with devastating consequences. Finally, the Secchia and Panaro rivers experienced levee-breach events in the past, even without overtopping and during the occurrence of floods with low-medium return periods. In particular, the most recent event that occurred in this area was the flood originated from a bank failure on the Secchia River in 2014 (Vacondio et al., 2016), which caused losses of roughly EUR 500 million. This event raised awareness of the huge damage caused by flooding and of the necessity of increasing flood preparedness in both public administrations and population.

\subsection{Set-up}

The computational domain was built based on the available $1 \mathrm{~m}$ resolution DTM of the riverbeds and of the floodable lowlands derived from LiDAR surveys carried out in the years 2008, 2015 and 2016. In order to avoid the excessive memory requirements and heavy computational costs (even for a fast GPU-parallel model), related to the adoption of a uniform $1 \mathrm{~m}$ mesh (which would require billions of cells), the DTM was downsampled to a resolution of $5 \mathrm{~m}$. This operation did not affect the crest elevation of the artificial embankments. In fact, each $5 \mathrm{~m} \times 5 \mathrm{~m}$ cell crossed by an embankment was identified, and its elevation was set equal to the maximum value among the original 25 points belonging to that cell; otherwise, its elevation was simply computed as the average of the 25 terrain data comprised in that cell. For other urban features that were not captured correctly by the LiDAR survey, additional corrections were introduced manually.

Then, the study domain was discretized by means of a non-uniform BUQ grid: the maximum resolution $(5 \mathrm{~m})$ was forced along the riverbed, the levees, the main artificial embankments and channels, and at the breach location, whereas for rural areas it gradually decreased up to $40 \mathrm{~m}$ according to the algorithm presented by Vacondio et al. (2017). The resulting computational grid (Fig. 2), whose spatial resolution is considered suitable for the detailed modelling of the river and the lowland area, consists of roughly $13 \times 10^{6}$ cells, and the number of cells is reduced by approximately $70 \%$ compared to a uniform $5 \mathrm{~m}$ mesh.

The study area also includes several urban settlements: Modena, with about 185000 inhabitants, is the most populated one, and its old city centre comprises narrow streets, which cannot be accurately described with a $5 \mathrm{~m}$ resolution. Therefore, limited to the few scenarios concerning the flooding of Modena, simulations were performed using a finer mesh (up to $2.5 \mathrm{~m}$ ) in the town, and the urban layout was modelled according to the "building hole" method (Schubert and Sanders, 2012), in order to capture the flow field inside the urban area correctly.

Buildings were explicitly resolved only for the city of Modena, whereas, according to previous findings (Vacondio et al., 2016), the presence of the other (smaller) settle- 


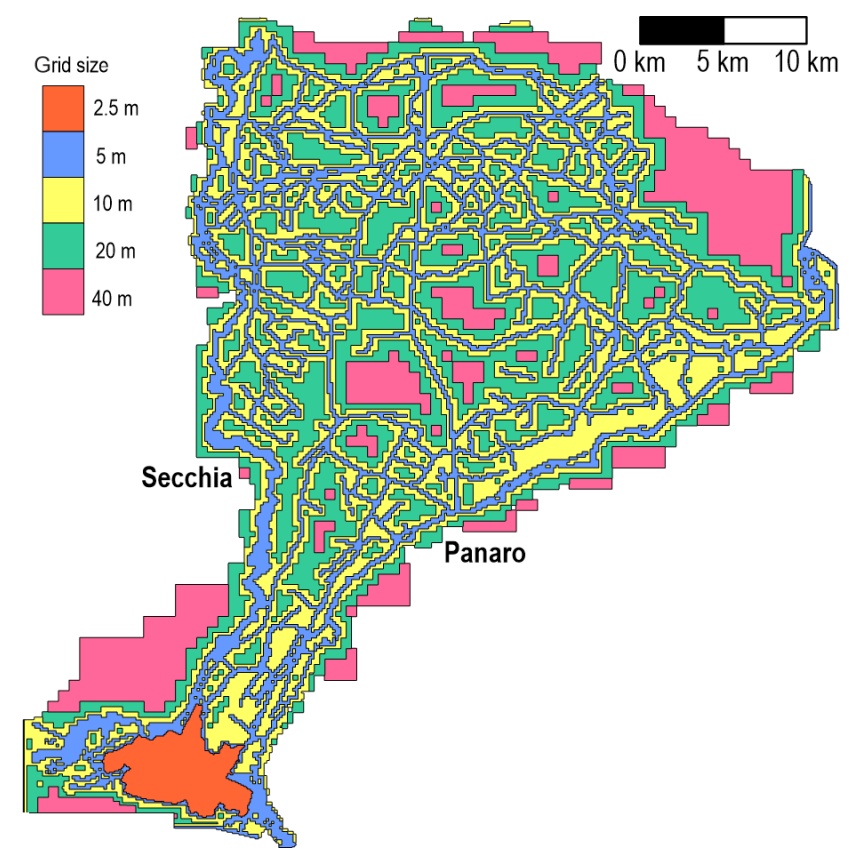

Figure 2. Multiresolution computational grid for the pilot area.

ments was taken into account by means of a higher resistance parameter ("building resistance" method; Schubert and Sanders, 2012). In particular, the roughness coefficient for the urban areas was calibrated based on the event that occurred in 2014 (the flood arrival times at selected locations were known) and was set equal to $0.14 \mathrm{~m}^{-1 / 3} \mathrm{~s}$, while for rural areas a Manning coefficient of $0.05 \mathrm{~m}^{-1 / 3} \mathrm{~s}$ was chosen. In the absence of data for calibration concerning past flooding events, land use maps can be exploited to assign standard roughness values from the literature.

As for the river roughness, the calibration for the Secchia River was performed in previous works (Vacondio et al., 2016) based on the water levels recorded at the available gauging stations during recent flood events. A Manning coefficient equal to $0.05 \mathrm{~m}^{-1 / 3} \mathrm{~s}$ provided the best results. The roughness of the Panaro River was also subject to calibration with a similar procedure, and the value $0.04 \mathrm{~m}^{-1 / 3} \mathrm{~s}$ was selected.

With regard to the selection of the hydrological scenarios for the two rivers, the synthetic design hydrographs (Tomirotti and Mignosa, 2017) with assigned return periods were considered. After preliminary simulations, inflow A (overtopping-induced flooding) was identified as the 50-year return period hydrograph for the Secchia River and as the 100-year one for the Panaro River. Then, the inflow hydrograph with a 20-year return period was selected as inflow B for both rivers in order to consider an event with higher frequency. These discharge hydrographs were assumed as upstream boundary conditions during the simulations.

The downstream section was located at the confluence (of the Secchia and Panaro rivers) into the Po River, and a con- stant water level in this (much larger) river, which did not affect the breach outflow even for the most downstream breach location, was assumed as the boundary condition.

As mentioned before, the pilot area can be flooded by hypothetical failures occurring along the Secchia and Panaro rivers. Assuming a distance of about $2 \mathrm{~km}$ from one breach to the other, 30 breach locations were identified along the right levee of the Secchia River (for the flooding scenarios related to this river) and 26 ones along the left levee of the Panaro River. Figure 1 reports all the 56 simulated breach sites. Among these, eight breach scenarios on the Secchia River and four on the Panaro River involve the city of Modena. Based on past observations, the breach final width was assumed equal to $100 \mathrm{~m}$ for all scenarios, while the opening time was set equal to 3 or $6 \mathrm{~h}$ for inflows $\mathrm{A}$ and $\mathrm{B}$, respectively.

All the 112 simulations (56 breach locations and two hydrological scenarios) were prolonged for $72 \mathrm{~h}(3 \mathrm{~d})$ because at that point the outflow from the breach was almost null, the flooded area had reached its maximum extension and no significant flow dynamics can be observed.

\subsection{Outcomes}

Figure 3 shows an example of the results for one scenario on the Secchia River. The maps of maximum water depths shown in Fig. 3a reveals that the flooding involves the northern portion of the domain, partially affecting some urban settlements (S. Possidonio and Mirandola), while villages in the east are safe from this inundation and could temporarily host the evacuated population. The maximum velocity magnitude (Fig. 3b) remains below $1 \mathrm{~m} \mathrm{~s}^{-1}$, except for the surroundings of the breach and close to some road embankments that are overtopped by water (see detail in Fig. 3b), where drivers can be in grave danger. The combination of water depth and velocity (Fig. 3c) highlights that lowland areas are mostly affected with low (green $0 \leq D<0.5 \mathrm{~m}$ ) and medium (yellow $0.5 \mathrm{~m} \leq D<1 \mathrm{~m}$ ) total depth values, even if higher values (orange $1 \mathrm{~m} \leq D<1.5 \mathrm{~m}$ and red $D \geq 1.5 \mathrm{~m}$ ) are reached where high water depths are observed. The map of flood arrival times in Fig. 3d shows that, for this scenario, approximately $45 \%$ of the flooded area is affected $24 \mathrm{~h}$ after the breach opening (purple contour line), guaranteeing a considerable amount of time for emergency activities. It is relevant to note that also during the levee breach occurred in 2014 on the Secchia River (Vacondio et al., 2016) one of the most affected villages was flooded the day after the opening, but no countermeasures were taken at that time, since a priori knowledge of the inundation dynamics was not available. Finally, a video showing the flooding evolution for this scenario is provided as additional material.

In addition to the maps representing specific hydraulic indicators for each scenario, further information can be obtained by analysing the results of the whole database. In particular, the most affected parts in the pilot area and those 

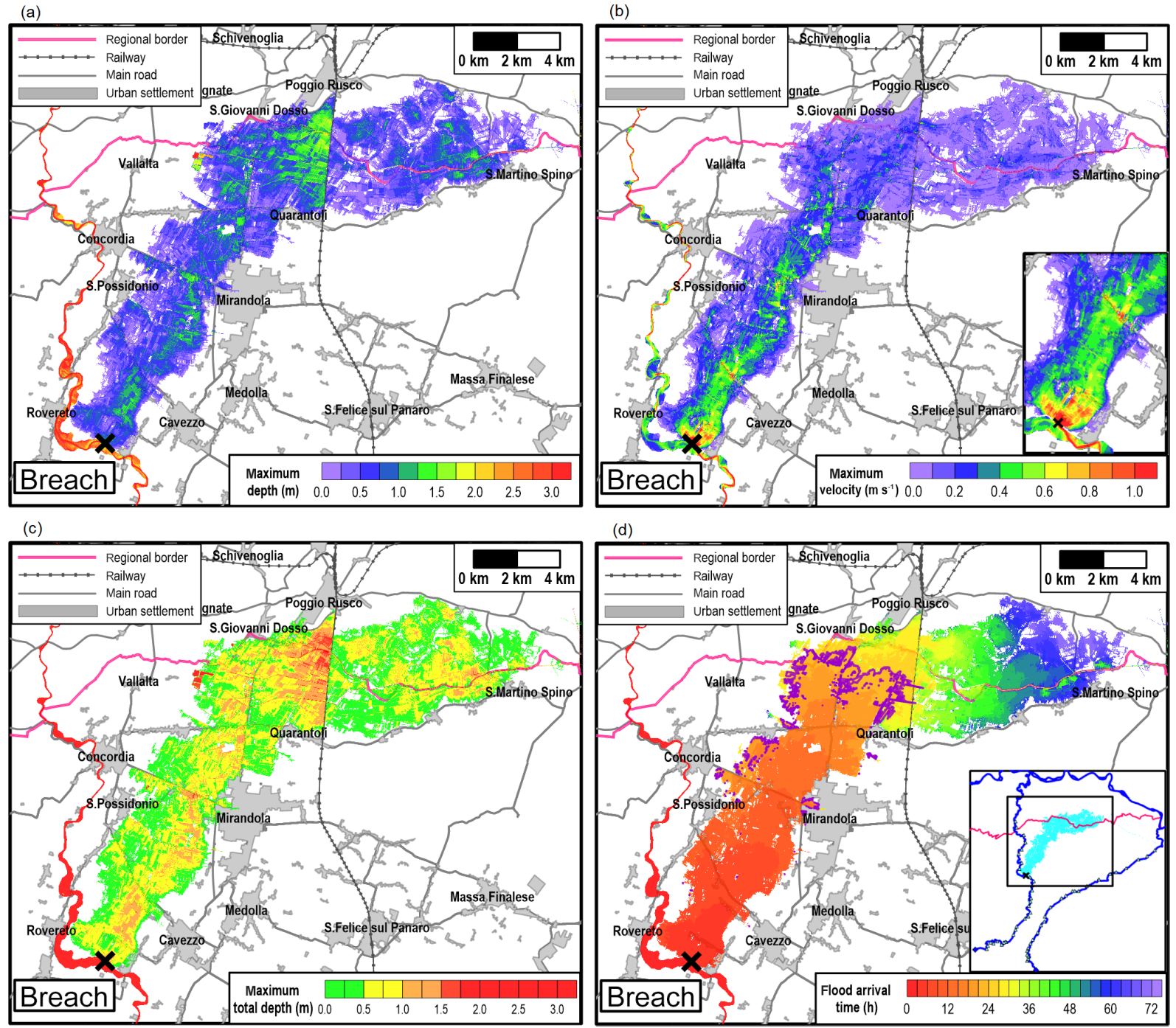

Figure 3. Example of the resulting maps concerning the maximum (a) water depth, (b) velocity, (c) total depth and (d) flood arrival time for a given scenario on the Secchia River with inflow B. The main roads, railways and urban settlements are identified, and the breach location is indicated with a black cross. The topographic information in background is made available by Emilia-Romagna region at https: //geoportale.regione.emilia-romagna.it/it (last access: 8 January 2020).

never hit by flooding can be investigated. Therefore, for both inflows $\mathrm{A}$ and $\mathrm{B}$, the maps of the inundated areas were combined in order to quantify the number of scenarios affecting each computational cell in the domain. Figure 4 shows the resulting map for inflow $\mathrm{B}$ : in this case, about $50 \%$ of the pilot area is affected by at least one breach scenario. In particular, two areas can be identified as being most affected by the possible flooding induced by levee breaching, since up to 21 breach scenarios (from both the Secchia and the Panaro River) involve these regions. On the other hand, it can be observed that there is a large zone, in the middle of the pilot area, that is not affected by any of the considered breach scenarios thanks to the favourable terrain topography; hence, it is potentially recommended for evacuation purposes (e.g. organization of assembly points).

\section{Discussion}

Due to climate change and population growth, structural protection systems such as levees have been often adopted to increase protection against floods. However, this kind of defence presents several ecological (e.g. hydraulic decoupling between the river and its floodplain, loss of biodiversity, change in groundwater levels, and increase in greenhouse gas emission) and socio-economic consequences (Auerswald et al., 2019).

Focusing on the "levee effect" and on the issue of adequately considering the residual flood risk related to levees, the main goal of this paper was to define a methodology based on the use of numerical models to enhance the resilience of lowland areas in case of levee-breach occurrence. 


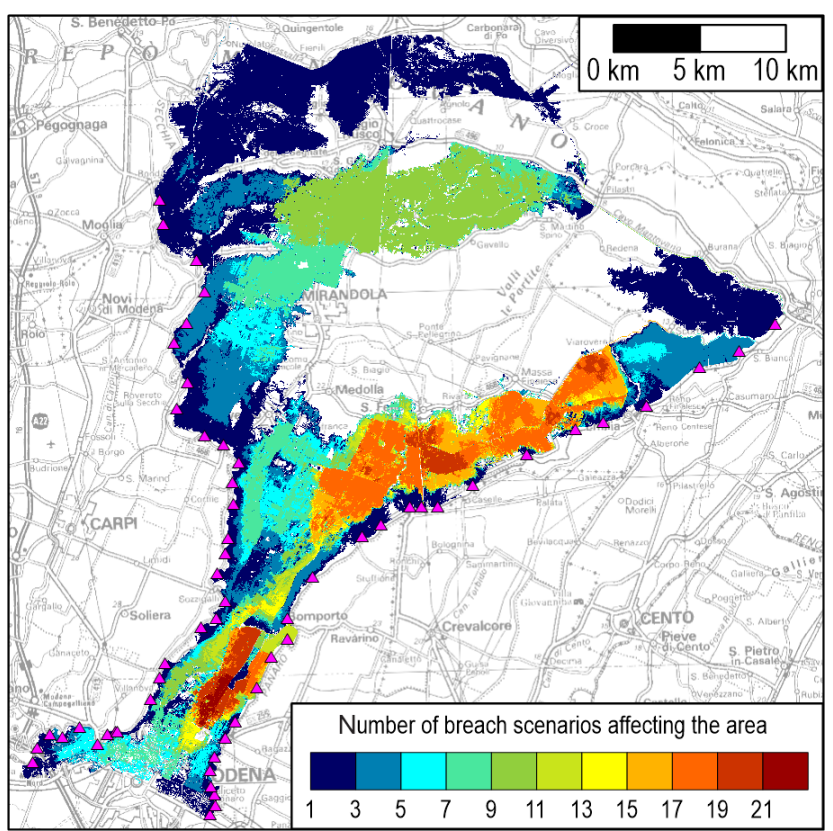

Figure 4. Number of flooding scenarios affecting each cell of the pilot area with inflow B. Two portions of the domain (in red) are flooded for 21 scenarios (from either the Secchia or the Panaro River), while the uncoloured zones are never inundated. The topographic map in background is made available by Emilia-Romagna region at https://geoportale.regione.emilia-romagna.it/it (last access: 8 January 2020).

The procedure, which requires the numerical simulation of many scenarios with different breach locations and hydrological inputs, is applicable to lowland areas protected from flooding by river levees, which can be inundated in case of embankment collapse.

In the context of emergency planning, the creation of a large database of scenarios represents the main alternative solution when real-time simulations cannot be performed (e.g. when weather forecast systems or direct measurements are missing or simply cannot provide reliable predictions of the incoming flow hydrograph in small river basins). This means that, when a flooding event occurs, the results of the closest simulated scenario can be accessed in order to predict the inundation pattern and to better organize the civil protection activities and take timely countermeasures. Besides these emergencies, the results of each simulation, also combined for global considerations, allow for an improvement of evacuation and defence system planning. In this context, advanced optimization-based tools and algorithms (Dulebenets et al., 2019a, b) can be exploited to create emergency evacuation plans that efficiently minimize individuals' travel time during a natural hazard.

Moreover, the simulation results can be useful for updating the alert systems as well as for the dissemination of the correct behaviour to local inhabitants. In the framework of adaptation management, recently, the LIFE PRIMES project
(LIFE PRIMES, 2019) contributed to building resilient communities in other areas in the Emilia-Romagna region by raising their awareness and proactive participation in the operations of early warning.

In this framework, the availability of high-resolution DTMs, which can describe the local terrain features in detail, represents a relevant tool. Focusing on numerical modelling, the adoption of a fully 2-D SWE model was claimed not only for capturing the complex hydrodynamic field near the breach but also the wet-dry front propagation over an irregular topography. The only drawback of this kind of model, which is the long computational time, was overcome by taking advantage of a parallelized code such as PARFLOOD. Simulations were performed using a NVIDIA ${ }^{\circledR}$ Tesla ${ }^{\circledR}$ P100 GPU. Runtimes range approximately between 1 and $5 \mathrm{~h}$, depending on the extent of the flooded area. The ratio of physical time to computational time is between 15 and 80 and confirms the high efficiency of GPUaccelerated codes for flood simulation, even for large highresolution domains. If high-performance computing (HPC) clusters equipped with 20 to 50 GPUs could be exploited, the simulation of the whole database of 112 scenarios would only require 18 to $9 \mathrm{~h}$ of computation, assuming an average runtime of $3 \mathrm{~h}$.

With reference to the assessment of flooding scenarios involving urban settlements, the use of a fully 2-D model and a high-resolution mesh is required. In particular, a grid size of the order of 2-3 $\mathrm{m}$ becomes crucial when dealing with historical towns. Evidence of this requirement is shown in Fig. 5 with regard to the potential flooding of the city of Modena, whose urban layout was modelled with a $2.5 \mathrm{~m}$ resolution mesh using the building hole approach. The backwater effect caused by buildings and the high flow velocities $\left(>1 \mathrm{~m} \mathrm{~s}^{-1}\right)$ along some streets can be observed. Near the historical centre, streets are very narrow, and the complex hydrodynamic field could hardly be captured using a coarser mesh.

Still focusing on topographic information and spatial resolution, it is relevant to note that drainage networks with relatively narrow channels were not described in detail in the computational grid. In fact, even though microtopography (i.e. tillage feature and ditches) determines preferential pathways for very shallow flows (Viero and Valipour, 2017; Hailemariam et al., 2014), the maximum discharge through the breaches considered here (of the order of $10^{2} \mathrm{~m}^{3} \mathrm{~s}^{-1}$ ) largely exceeds the discharge capacity of the drainage systems. Moreover, most of the minor channels are equipped with sluice gates that are kept closed during river floods, preventing the drainage of the flooded volume until the end of the event. As a result, these networks were not expected to contribute to the flood dynamics significantly, and hence they were neglected in the terrain description. Finally, it must be stressed that the database should be updated periodically to take into account possible significant changes to the landscape (i.e. construction and removal of relevant embank- 

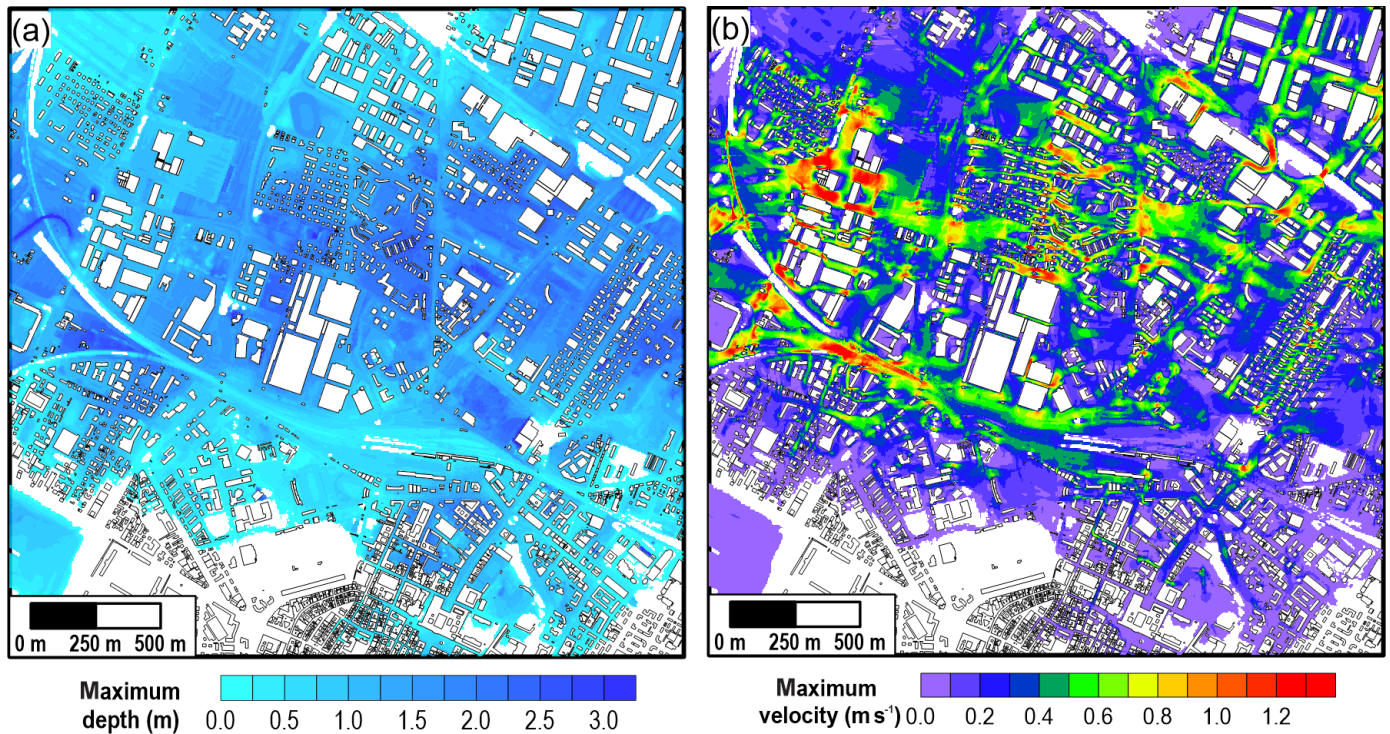

Figure 5. Detail of the complex hydrodynamic field in the city of Modena: maximum water (a) depth and (b) velocity for one breach scenario on the Secchia River.

ments) that are expected to affect the flood dynamic (Viero et al., 2019).

Further considerations are required regarding the assumptions concerning the levee-breach locations and dimensions for the simulated scenarios. First, focusing on the selection of the breach position, a distance of about $2 \mathrm{~km}$ between two consecutive sites was chosen. This pitch represents a compromise between the number of simulations to be performed (not so much for reducing the computational time as for achieving a "manageable" number of scenarios for output analysis) and the possibility of capturing all the inundation patterns. In fact, while two close breaches often generate similar flooded areas, sometimes the flooding evolution may change dramatically even for relatively close breaches. As an example, Fig. 6 compares the inundated areas for two breach scenarios on the Secchia River, which are remarkably different: in the first case, the lowland area towards the east is involved, whereas for the breach site immediately downstream, the flooding moves northwards due to the terrain morphology. This behaviour confirms that the levee-breach locations should be carefully considered.

With regard to the geometrical parameters assumed for the breach evolution, a sensitivity analysis on the breach final width and opening time was carried out, and the results for a given breach location on the Secchia River (see Fig. 3) are reported in Table 1 for inflows A and B. Maintaining the reference opening time $T$ ( $3 \mathrm{~h}$ for inflow A and $6 \mathrm{~h}$ for inflow $\mathrm{B}$ ), additional tests were performed by varying the assumed final width $L(100 \mathrm{~m})$ by $\pm 30 \%(L=70,130 \mathrm{~m})$. With regard to the opening time, $\pm 50 \%$ variations were explored (i.e. $T=1.5,4.5 \mathrm{~h}$, for inflow A and $T=3,9 \mathrm{~h}$, for inflow B), considering a fixed value for the breach width

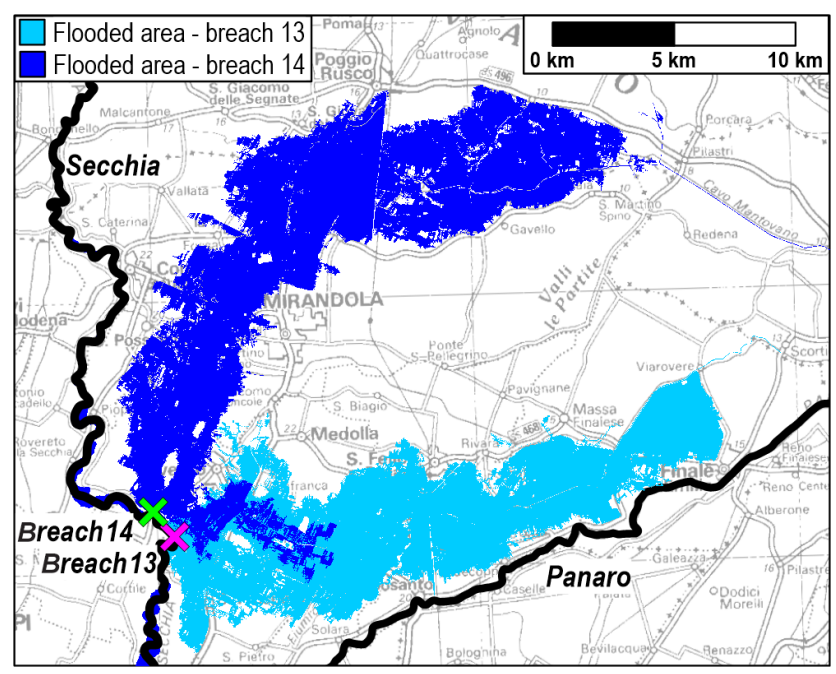

Figure 6. Example of the simulated flooded areas generated by two consecutive breaches (nos. 13 and 14) on the Secchia River (the breach positions are indicated by crosses) for inflow B: the first breach scenario (cyan) mainly involves the eastern part of the domain, whereas the inundation for the second one (blue) moves northwards. The topographic map in background is made available by Emilia-Romagna region at https://geoportale.regione. emilia-romagna.it/it (last access: 8 January 2020).

( $L=100 \mathrm{~m}$ ). The total volume flowing out of the breach and the extent reached by flooding at fixed times $(24,48$ and $72 \mathrm{~h}$ after the breach opening) were used for comparing the different configurations. As expected, the results show that a larger breach, as well as a reduced opening time, slightly increases the flooded volume and area. However, the relative 
Table 1. Sensitivity analysis on the final breach width $L$ and opening time $T$ for one scenario on the Secchia River (see Fig. 3), with both inflows A and B. Results are compared based on the total outflow volume (vol) and the flooded area 24,48 and $72 \mathrm{~h}$ after the breach opening $\left(\operatorname{area}_{24}, \operatorname{area}_{48}\right.$ and area $_{72}$, respectively). Their relative differences ( $\Delta$ vol, $\Delta$ area $_{24}, \Delta$ area $_{48}$ and $\Delta$ area 72$)$ with reference to the baseline simulation are also reported for each tested configuration.

\begin{tabular}{lrrrrrrrrrr}
\hline Inflow & $\begin{array}{r}L \\
(\mathrm{~m})\end{array}$ & $\begin{array}{r}T \\
(\mathrm{~h})\end{array}$ & $\begin{array}{c}\text { vol } \\
\left(10^{6} \mathrm{~m}^{3}\right)\end{array}$ & $\begin{array}{r}\Delta \text { vol } \\
(\%)\end{array}$ & $\begin{array}{r}\text { area } 24 \\
\left(\mathrm{~km}^{2}\right)\end{array}$ & $\begin{array}{r}\Delta \text { area } 24 \\
(\%)\end{array}$ & $\begin{array}{r}\text { area } 48 \\
\left(\mathrm{~km}^{2}\right)\end{array}$ & $\begin{array}{r}\Delta \text { area } 48 \\
(\%)\end{array}$ & $\begin{array}{r}\text { area72 } \\
\left(\mathrm{km}^{2}\right)\end{array}$ & $\begin{array}{r}\Delta \text { area72 } \\
(\%)\end{array}$ \\
\hline A & 100 & 3 & 52.75 & & 68.04 & & 99.08 & & 117.20 & \\
A & 70 & 3 & 48.35 & -8 & 63.52 & -7 & 93.89 & -5 & 111.99 & -4 \\
A & 130 & 3 & 55.09 & 4 & 70.11 & 3 & 101.55 & 2 & 120.29 & 3 \\
A & 100 & 1.5 & 54.31 & 3 & 69.53 & 2 & 100.55 & 1 & 119.05 & 2 \\
A & 100 & 4.5 & 51.19 & -3 & 65.97 & -3 & 97.59 & -2 & 115.39 & -2 \\
\hline B & 100 & 6 & 38.24 & & 56.78 & & 84.07 & & 101.67 & \\
B & 70 & 6 & 35.20 & -8 & 51.71 & -9 & 80.00 & -5 & 96.47 & -5 \\
B & 130 & 6 & 39.89 & 4 & 58.99 & 4 & 86.54 & 3 & 104.71 & 3 \\
B & 100 & 3 & 41.00 & 7 & 61.02 & 7 & 87.94 & 5 & 105.83 & 4 \\
B & 100 & 9 & 35.51 & -7 & 50.92 & -10 & 80.52 & -4 & 97.40 & -4 \\
\hline
\end{tabular}

differences against the baseline simulation always remain below $10 \%$ : this confirms that the flooding scenarios are only marginally (less than linearly) influenced by the values assumed by these parameters.

Moreover, considering constant breach parameters $(L=$ $100 \mathrm{~m}, T=3 \mathrm{~h}$ ), data reported in Table 1 also give an idea of the influence of the inflow condition on flooding results for this scenario: unsurprisingly, the total flooded volume for inflow B is $22 \%$ lower compared to inflow A, but the final flooded area is only $10 \%$ smaller. This means that breaching during a flood event with a higher return period generates a more severe inundation on the lowland (i.e. higher water depths), while the affected area may be somewhat less influenced due to the terrain morphology and to the possible presence of obstacles that limit the flood propagation. This outcome is encouraging for the purpose of this work because even for an actual flood event, whose inflow hydrograph can be quite different from the design hydrograph with assigned return period used for creating the database, at least the area possibly hit by flooding may be identified reasonably.

In this study, scenarios are not associated to their probability of occurrence, i.e. all breach locations are considered equally probable. This is consistent with the purpose of the methodology. However, if the same database of simulations had to be exploited for flood hazard (or even flood risk) assessment in the same area, information about the failure probability of the levee for each scenario would be required. This probability can be estimated by means of "fragility curves" for different levee failure mechanisms (Apel et al., 2006; Vorogushyn et al., 2010; Mazzoleni et al., 2013; Pinter et al., 2016), sometimes called "levee failure functions", which depend both on the water level in the river and on the levee geometrical and geotechnical characteristics (often unknown). This analysis is beyond the scope of this paper and is left to future developments.

\section{Conclusions}

With the aim of enhancing the resilience of lowland areas in case of levee-breach occurrence, this paper defined a methodology for creating a database of hypothetical flood scenarios obtained from 2-D numerical modelling, associated with different hydrological configurations and breach locations. The procedure, named RESILIENCE, was applied to a pilot area of about $1100 \mathrm{~km}^{2}$ in northern Italy, but it can be extended to any other leveed river. The computational efficiency ensured by the adoption of the PARFLOOD parallel code allowed for the use of a high-resolution mesh (up to $2.5-5 \mathrm{~m}$ ), while ratios of physical to computational time up to 80 were reached for some simulations. The application of numerical models to predict the flood dynamics provides useful data for emergency planning and management and represents a fundamental tool for civil protection purposes and for increasing flood preparedness. Future developments of the methodology include the expansion of the current database for the pilot area (e.g. other hydrological inputs, breaching along the Po River and multiple breach openings), the identification of the most probable failure locations, and the application of the RESILIENCE procedure to other rivers and lowland areas. Finally, support and assistance will be provided to public administrations for the correct interpretation and employment of the simulation results during civil protection planning.

Data availability. The data set developed for this research is available upon request to the author and approval by the funding agency. The PARFLOOD model is available for non-commercial scientific collaboration upon request from Renato Vacondio (renato.vacondio@unipr.it). 
Video supplement. A simulation visualization of a hypothetical levee-breach-induced flooding on the Secchia River is available as additional material at https://doi.org/10.5446/44534.

Author contributions. PM and RV designed the RESILIENCE project and identified the pilot area. RV, SD, AF and PM contributed to the implementation of the PARFLOOD 2-D SWE code. AF initially calibrated the Secchia River model, while SD calibrated the Panaro River model and carried out all the levee-breach simulations. $\mathrm{AF}$ and SD wrote the paper, in consultation with RV and PM. All authors reviewed the final paper.

Competing interests. The authors declare that they have no conflict of interest.

Acknowledgements. The Interregional Agency for the Po River (Agenzia Interregionale per il fiume Po) and the Po River Basin Authority (Autorità di Bacino distrettuale del fiume Po) are gratefully acknowledged for providing data for the Secchia and Panaro rivers.

This research benefits from the HPC (High Performance Computing) facility of the University of Parma. The authors are grateful to the editor and the reviewers for their constructive comments on the early version of this paper.

Financial support. This work was financially supported by the Territorial Safety and Civil Protection Agency of Emilia-Romagna Region (Agenzia per la Sicurezza Territoriale e la Protezione Civile della Regione Emilia-Romagna). The publication of this paper was financially supported by the Center for Studies in European and International Affairs (CSEIA) of the University of Parma under the OPEN-UP (Outgoing Publications, Essays and Networks) call. This work was partially supported by Ministry of Education, Universities and Research under the Scientific Independence of young Researchers project (grant no. RBSI14R1GP, CUP code D92I15000190001).

Review statement. This paper was edited by Paolo Tarolli and reviewed by two anonymous referees.

\section{References}

Alfieri, L., Feyen, L., Dottori, F., and Bianchi, A.: Ensemble flood risk assessment in Europe under high end climate scenarios, Global Environ. Change, 35, 199-212, 2015.

Alkema, D. and Middelkoop, H.: The influence of floodplain compartmentalization on flood risk within the Rhine-Meuse Delta, Nat. Hazards, 36, 125-145, 2005.

Apel, H., Thieken, A. H., Merz, B., and Blöschl, G.: Flood risk assessment and associated uncertainty, Nat. Hazards Earth Syst. Sci., 4, 295-308, https://doi.org/10.5194/nhess-4-2952004, 2004.
Apel, H., Thieken, A. H., Merz, B., and Blöschl, G.: A probabilistic modelling system for assessing flood risks, Nat. Hazards, 38, 79100, 2006.

Arrighi, C., Pregnolato, M., Dawson, R., and Castelli, F.: Preparedness against mobility disruption by floods, Sci. Total Environ., 654, 1010-1022, 2019.

Audusse, E., Bouchut, F., Bristeau, M.-O., Klein, R., and Perthame, B. T.: A fast and stable well-balanced scheme with hydrostatic reconstruction for shallow water flows, SIAM J. Scient. Comput., 25, 2050-2065, 2004.

Auerswald, K., Moyle, P., Seibert, S. P., and Geist, J.: HESS Opinions: Socio-economic and ecological trade-offs of flood management - benefits of a transdisciplinary approach, Hydrol. Earth Syst. Sci., 23, 1035-1044, https://doi.org/10.5194/hess-23-10352019, 2019.

Aureli, A., Maranzoni, A., Mignosa, P., and Ziveri, C.: Flood hazard mapping by means of fully-2D and quasi-2D numerical modeling: a case study, in: Floods, from defence to management, 3rd Iinternational Symposium on Flood Defence, Nijmegen, Netherlands, edited by: van Alphen, J., van Beek, E., and Taal, M., Taylor \& Francis/Balkema, Leiden, 373-382, 2005.

Aureli, F. and Mignosa, P.: Flooding scenarios due to levee breaking in the Po river, in: Proceedings of the Institution of Civil Engineers-Water Management, vol. 157, Thomas Telford Ltd, Scotland, 3-12, 2004.

Aureli, F., Maranzoni, A., Mignosa, P., and Ziveri, C.: 2D numerical modelling for hydraulic hazard assessment: A dam-break case study, in: Proc., Int. Conf. on Fluvial Hydraulics, River Flow 2008, Kubaba Congress Dept. and Travel Services, Ankara, Turkey, 729-736, 2008.

Black, H.: Unnatural disaster: human factors in the Mississippi floods, Environews Spheres Influ., 116, A390-A393, https://doi.org/10.1289/ehp.116-a390, 2008.

Bladé, E., Gómez-Valentín, M., Dolz, J., Aragón-Hernández, J., Corestein, G., and Sánchez-Juny, M.: Integration of 1D and 2D finite volume schemes for computations of water flow in natural channels, Adv. Water Resour., 42, 17-29, 2012.

Brodtkorb, A. R., Sætra, M. L., and Altinakar, M.: Efficient shallow water simulations on GPUs: Implementation, visualization, verification, and validation, Comput. Fluids, 55, 1-12, 2012.

Caleffi, V., Valiani, A., and Zanni, A.: Finite volume method for simulating extreme flood events in natural channels, J. Hydraul. Res., 41, 167-177, 2003.

Castro, M. J., Ortega, S., De la Asuncion, M., Mantas, J. M., and Gallardo, J. M.: GPU computing for shallow water flow simulation based on finite volume schemes, Comptes Rendus Mécanique, 339, 165-184, 2011.

Conde, D., Canelas, R. B., and Ferreira, R. M.: A high-performance model for shallow-water simulations in distributed and heterogeneous architectures, in: EGU General Assembly Conference Abstracts, 19, 17277, 2017.

Costabile, P., Costanzo, C., and Macchione, F.: Performances and limitations of the diffusive approximation of the 2-d shallow water equations for flood simulation in urban and rural areas, Appl. Numer. Math., 116, 141-156, 2017.

Dazzi, S., Vacondio, R., Dal Palù, A., and Mignosa, P.: A local time stepping algorithm for GPU-accelerated 2D shallow water models, AdvWater Resour., 111, 274-288, 2018. 
Dazzi, S., Vacondio, R., and Mignosa, P.: Integration of a Levee Breach Erosion Model in a GPU-Accelerated 2D Shallow Water Equations Code, Water Resour. Res., 55, 682-702, 2019.

De Bruijn, K. M.: Resilience and flood risk management. A systems approach applied to lowland rivers, $\mathrm{PhD}$ thesis, Technical University Delft, Delft, the Netherlands, 2005.

Di Baldassarre, G., Castellarin, A., and Brath, A.: Analysis of the effects of levee heightening on flood propagation: example of the River Po, Italy, Hydrolog. Sci. J., 54, 1007-1017, 2009.

Di Baldassarre, G., Viglione, A., Carr, G., Kuil, L., Yan, K., Brandimarte, L., and Blöschl, G.: Debates-Perspectives on sociohydrology: Capturing feedbacks between physical and social processes, Water Resour. Res., 51, 4770-4781, 2015.

D'Oria, M., Mignosa, P., and Tanda, M. G.: An inverse method to estimate the flow through a levee breach, Adv. Water Resour., 82, 166-175, 2015.

Dottori, F., Szewczyk, W., Ciscar, J.-C., Zhao, F., Alfieri, L., Hirabayashi, Y., Bianchi, A., Mongelli, I., Frieler, K., Betts, R. A., and Feyen, L.: Increased human and economic losses from river flooding with anthropogenic warming, Nat. Clim. Change, 8, 781-786, 2018.

Dulebenets, M. A., Abioye, O. F., Ozguven, E. E., Moses, R., Boot, W. R., and Sando, T.: Development of statistical models for improving efficiency of emergency evacuation in areas with vulnerable population, Reliabil. Eng. Syst. Safe., 182, 233-249, 2019a.

Dulebenets, M. A., Pasha, J., Abioye, O. F., Kavoosi, M., Ozguven, E. E., Moses, R., Boot, W. R., and Sando, T.: Exact and heuristic solution algorithms for efficient emergency evacuation in areas with vulnerable populations, Int. J. Disast. Risk Reduct., 39, 101114, https://doi.org/10.1016/j.ijdrr.2019.101114, 2019 b.

Faeh, R.: Numerical modeling of breach erosion of river embankments, J. Hydraul. Eng., 133, 1000-1009, 2007.

Ferrari, A., D’Oria, M., Vacondio, R., Dal Palù, A., Mignosa, P., and Tanda, M. G.: Discharge hydrograph estimation at upstreamungauged sections by coupling a Bayesian methodology and a 2D GPU shallow water model, Hydrol. Earth Syst. Sci., 22, 52995316, https://doi.org/10.5194/hess-22-5299-2018, 2018.

Ferrari, A., Viero, D. P., Vacondio, R., Defina, A., and Mignosa, P.: Flood inundation modeling in urbanized areas: A meshindependent porosity approach with anisotropic friction, Adv. Water Resour., 125, 98-113, 2019.

García-Feal, O., González-Cao, J., Gómez-Gesteira, M., Cea, L., Domínguez, J., and Formella, A.: An accelerated tool for flood modelling based on Iber, Water, 10, 1459, https://doi.org/10.3390/w10101459, 2018.

Gejadze, I. Y. and Monnier, J.: On a 2D 'zoom' for the 1D shallow water model: Coupling and data assimilation, Comput. Meth. Appl. Mech. Eng., 196, 4628-4643, 2007.

Govi, M. and Maraga, F.: Inundation on the Po Plain caused by levee breaches, Giornale di Geologia Applicata, 1, 167-176, 2005.

Hailemariam, F. M., Brandimarte, L., and Dottori, F.: Investigating the influence of minor hydraulic structures on modeling flood events in lowland areas, Hydrol. Process., 28, 1742-1755, 2014.

Heine, R. A. and Pinter, N.: Levee effects upon flood levels: an empirical assessment, Hydrol. Process., 26, 3225-3240, 2012.

Horritt, M. and Bates, P.: Evaluation of 1D and 2D numerical models for predicting river flood inundation, J. Hydrol., 268, 87-99, 2002.
Hunter, N., Bates, P., Neelz, S., Pender, G., Villanueva, I., Wright, N., Liang, D., Falconer, R. A., Lin, B., Waller, S., Crossley, A. J., and Mason, D.: Benchmarking 2D hydraulic models for urban flood simulations, Proceedings of the Institution of Civil Engineers, Water Managem., 161, 13-30, 2008.

Huthoff, F., Remo, J., and Pinter, N.: Improving flood preparedness using hydrodynamic levee-breach and inundation modelling: Middle Mississippi River, USA, J. Flood Risk Manage., 8, 2-18, 2015.

ISPRA: Hydrogeological instability in Italy: hazard and risk indicators, in: Vol. 287, Rome, ISBN 978-88-448-0901-0, 2018.

Jongman, B., Winsemius, H. C., Fraser, S. A., Muis, S., and Ward, P. J.: Assessment and Adaptation to Climate Change-Related Flood Risks, in: Oxford Research Encyclopedia of Natural Hazard Science, Oxford, https://doi.org/10.1093/acrefore/9780199389407.013.278, 2018.

Kamrath, P., Disse, M., Hammer, M., and Köngeter, J.: Assessment of discharge through a dike breach and simulation of flood wave propagation, Nat. Hazards, 38, 63-78, 2006.

Kundzewicz, Z. W., Pińskwar, I., and Brakenridge, G. R.: Large floods in Europe, 1985-2009, Hydrolog. Sci. J., 58, 1-7, 2013.

Kurganov, A. and Petrova, G.: A second-order well-balanced positivity preserving central-upwind scheme for the Saint-Venant system, Commun. Math. Sci., 5, 133-160, 2007.

Lacasta, A., Morales-Hernández, M., Murillo, J., and GarcíaNavarro, P.: An optimized GPU implementation of a 2D free surface simulation model on unstructured meshes, Adv. Eng. Softw., 78, 1-15, 2014.

Liang, Q. and Marche, F.: Numerical resolution of well-balanced shallow water equations with complex source terms, Adv. Water Resour., 32, 873-884, 2009.

Liang, Q., Du, G., Hall, J. W., and Borthwick, A. G.: Flood inundation modeling with an adaptive quadtree grid shallow water equation solver, J. Hydraul. Eng., 134, 1603-1610, 2008.

LIFE PRIMES: Preventing flooding RIsks by Making resilient communitiES, available at: http://ec.europa.eu/environment/life/ project/Projects/index.cfm?fuseaction=search.dspPage\&n_proj_ id=5247 (last access: 8 January 2020), 2019.

Masoero, A., Claps, P., Asselman, N. E., Mosselman, E., and Di Baldassarre, G.: Reconstruction and analysis of the Po River inundation of 1951, Hydrol. Process., 27, 1341-1348, 2013.

Mazzoleni, M., Bacchi, B., Barontini, S., Di Baldassarre, G., Pilotti, M., and Ranzi, R.: Flooding hazard mapping in floodplain areas affected by piping breaches in the Po River, Italy, J. Hydrol. Eng., 19, 717-731, 2013.

Md Ali, A., Solomatine, D. P., and Di Baldassarre, G.: Assessing the impact of different sources of topographic data on 1-D hydraulic modelling of floods, Hydrol. Earth Syst. Sci., 19, 631643, https://doi.org/10.5194/hess-19-631-2015, 2015.

Milanesi, L., Pilotti, M., and Ranzi, R.: A conceptual model of people's vulnerability to floods, Water Resour. Res., 51, 182-197, 2015.

Morales-Hernández, M., García-Navarro, P., Burguete, J., and Brufau, P.: A conservative strategy to couple 1D and 2D models for shallow water flow simulation, Comput. Fluids, 81, 26-44, 2013.

Nagy, L.: Estimating dike breach length from historical data, Period. Polytech. Civ. Eng., 50, 125-138, 2006. 
Neal, J., Villanueva, I., Wright, N., Willis, T., Fewtrell, T., and Bates, P.: How much physical complexity is needed to model flood inundation?, Hydrol. Process., 26, 2264-2282, 2012.

Orlandini, S., Moretti, G., and Albertson, J. D.: Evidence of an emerging levee failure mechanism causing disastrous floods in Italy, Water Resour. Res., 51, 7995-8011, 2015.

Paprotny, D., Sebastian, A., Morales-Nápoles, O., and Jonkman, S. N.: Trends in flood losses in Europe over the past 150 years, Nat. Commun., 9, 1985, https://doi.org/10.1038/s41467-018-042531, 2018.

Pinter, N., Huthoff, F., Dierauer, J., Remo, J. W., and Damptz, A.: Modeling residual flood risk behind levees, Upper Mississippi River, USA, Environ. Sci. Policy, 58, 131-140, 2016.

Qi, H. and Altinakar, M. S.: A GIS-based decision support system for integrated flood management under uncertainty with two dimensional numerical simulations, Environ. Model. Softw., 26, 817-821, 2011.

Sætra, M. L., Brodtkorb, A. R., and Lie, K.-A.: Efficient GPUimplementation of adaptive mesh refinement for the shallowwater equations, J. Scient. Comput., 63, 23-48, 2015.

Sanders, B. F., Schubert, J. E., and Detwiler, R. L.: ParBreZo: A parallel, unstructured grid, Godunov-type, shallow-water code for high-resolution flood inundation modeling at the regional scale, Adv. Water Resour., 33, 1456-1467, 2010.

Schubert, J. E. and Sanders, B. F.: Building treatments for urban flood inundation models and implications for predictive skill and modeling efficiency, Adv. Water Resour., 41, 49-64, 2012.

Singh, A., Porey, P., and Raju, K. R.: Criterion for location of downstream control for dynamic flood routing, J. Hydrol., 196, 66-75, 1997.

Tarrant, O., Todd, M., Ramsbottom, D., and Wicks, J.: 2D floodplain modelling in the tidal Thames - addressing the residual risk, Water Environ. J., 19, 125-134, 2005.
Teng, J., Jakeman, A. J., Vaze, J., Croke, B. F., Dutta, D., and Kim, S.: Flood inundation modelling: A review of methods, recent advances and uncertainty analysis, Environ. Model. Softw., 90, 201-216, 2017.

Tomirotti, M. and Mignosa, P.: A methodology to derive Synthetic Design Hydrographs for river flood management, J. Hydrol., 555, 736-743, 2017.

Toro, E. F.: Shock-capturing methods for free-surface shallow flows, John Wiley, New York, 2001.

Vacondio, R., Dal Palù, A., and Mignosa, P.: GPU-enhanced finite volume shallow water solver for fast flood simulations, Environ. Model. Softw., 57, 60-75, 2014.

Vacondio, R., Aureli, F., Ferrari, A., Mignosa, P., and Dal Palù, A.: Simulation of the January 2014 flood on the Secchia River using a fast and high-resolution 2D parallel shallow-water numerical scheme, Nat. Hazards, 80, 103-125, 2016.

Vacondio, R., Dal Palù, A., Ferrari, A., Mignosa, P., Aureli, F., and Dazzi, S.: A non-uniform efficient grid type for GPU-parallel Shallow Water Equations models, Environ. Model. Softw., 88, 119-137, 2017.

Viero, D. P. and Valipour, M.: Modeling anisotropy in free-surface overland and shallow inundation flows, Adv. Water Resour., 104, 1-14, 2017.

Viero, D. P., D’Alpaos, A., Carniello, L., and Defina, A.: Mathematical modeling of flooding due to river bank failure, Adv. Water Resour., 59, 82-94, 2013.

Viero, D. P., Roder, G., Matticchio, B., Defina, A., and Tarolli, P.: Floods, landscape modifications and population dynamics in anthropogenic coastal lowlands: The Polesine (northern Italy) case study, Sci. Total Environ., 651, 1435-1450, 2019.

Vorogushyn, S., Merz, B., Lindenschmidt, K.-E., and Apel, H.: A new methodology for flood hazard assessment considering dike breaches, Water Resour. Res., 46, W08541, https://doi.org/10.1029/2009WR008475, 2010. 